\title{
Experiences of Weight-Based Oppression in Qatar
}

Bayan Alajaimi, Undergraduate Student of Public Health, Qatar University

Bayan Alshowaikh, Undergraduate Student of Public Health, Qatar University

Dr Lily O'Hara, Associate Professor of Public Health, Qatar University

\section{Introduction}

Weight-based oppression is a widespread phenomenon in Western countries. ${ }^{1}$ External sources of weight-based oppression include exposure to stigmatizing or exclusionary social, cultural, economic, political and built environments, weight bias and discrimination, and weight-based bullying and violence. ${ }^{2,3}$ Internal sources of weight-based oppression are the internalized negative attitudes, values and beliefs people hold about body weight. ${ }^{2,3}$

Weight-based oppression is associated with a range of psychological, ${ }^{2}$ physiological and behavioral harms ${ }^{5}$ such as depression, anxiety, disordered eating, ${ }^{4}$ hypertension, allostatic load, cortisol reactivity ${ }^{5}$ and oxidative stress. ${ }^{6}$

Research on weight-based oppression is largely absent from the Arab region.

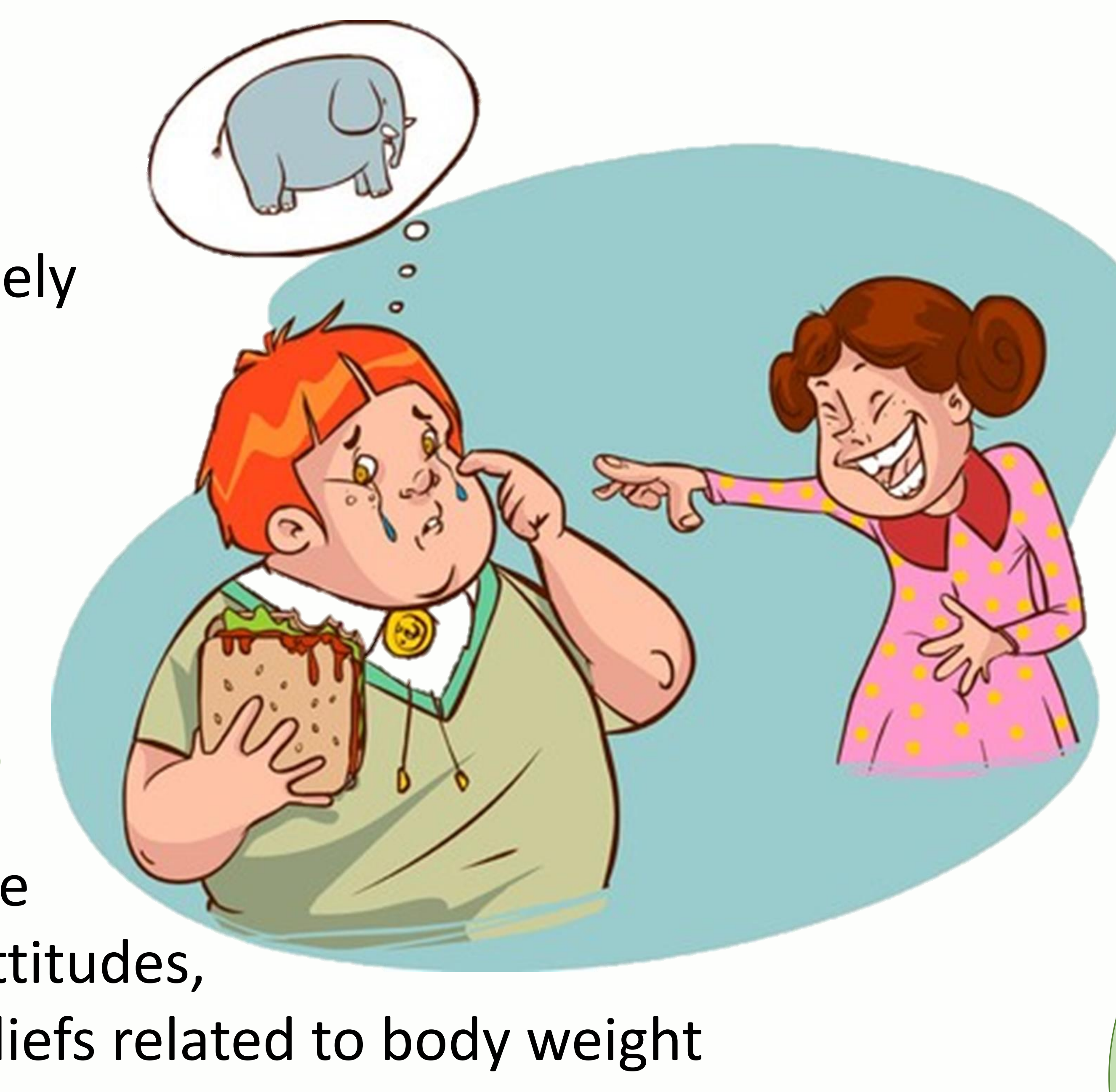

- To examine the experiences of external weight based oppression, including teasing, bullying, stigmatization, and discrimination in a diverse sample of people in Qatar

\section{Methods}

In-depth semi-structured interviews were used to provide a rich understanding of the views and experiences of participants recruited from staff, faculty and students at Qatar University using convenience and snowball sampling. The study was approved by the QUIRB, approval number 1070-EA/19.

\section{Results}

Participants ( 25 females, 4 males), were mostly Arabic, and aged between 18-53 years. Internal and external weight-based oppression were experienced by all participants and regarded as so common as to be normative. There were four major themes relating to internalised feelings about participants' bodies, and the timing, source and impact of exposure to external oppression.

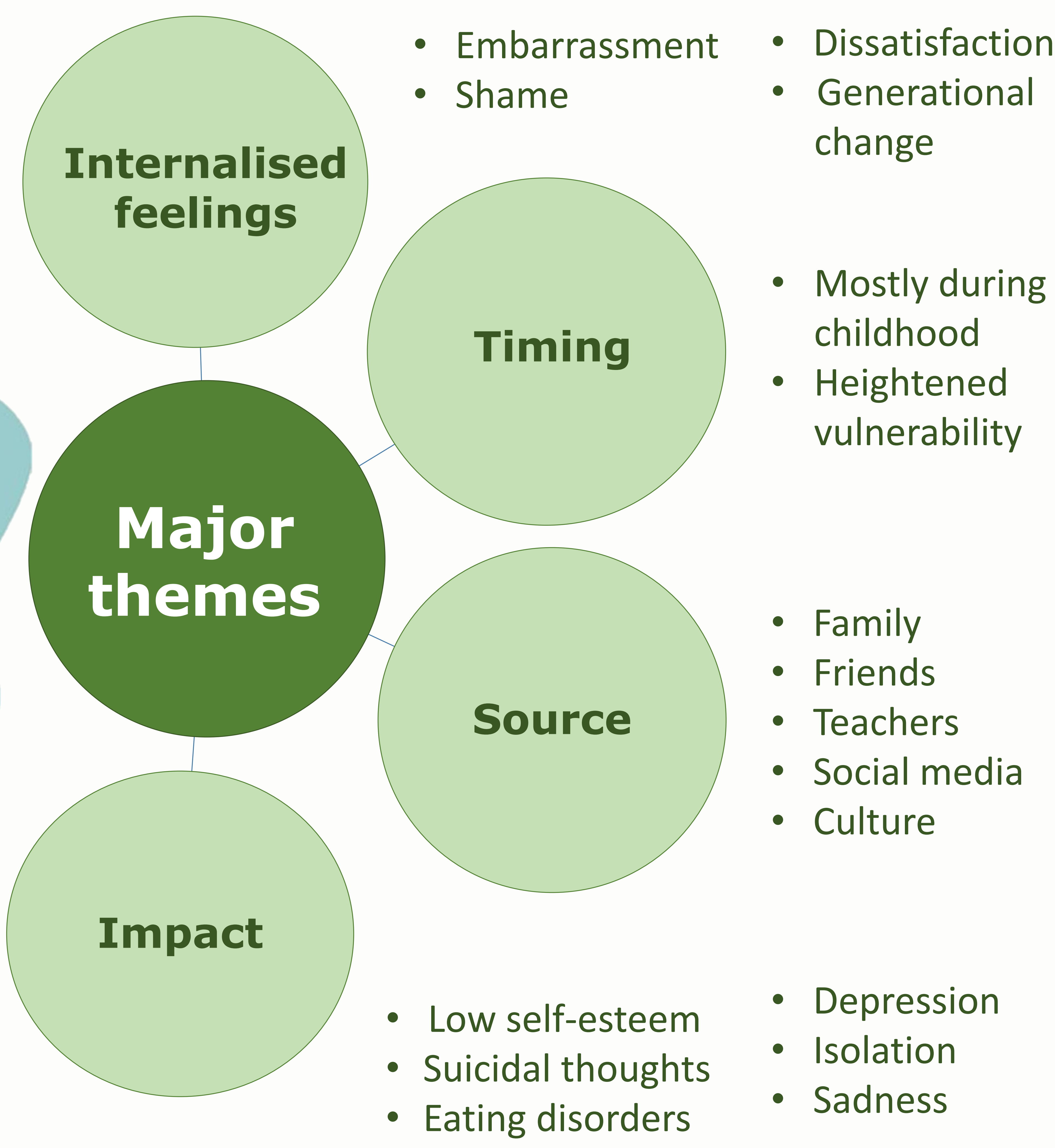

\section{Conclusion}

Weight-based oppression in the Middle East is an important and unrecognized public health issue. Programs should be developed to reduce exposure to weight-based oppression in all sectors. Reducing teasing, bullying and negative experiences related to body weight in childhood should be a priority.

\section{References}

1. Puhl, R.M., et al., A multinational examination of weight bias: predictors of anti-fat attitudes across four countries. International Journal of Obesity, 2015: p. 1-8.

2. Davison, K.K., et al., Overweight Girls Who Internalize Fat Stereotypes Report Low Psychosocial Well-being. Obesity, 2008. 16(S2): p. S30-S38.

3. Wang, S., K. Brownell, and T. Wadden, The influence of the stigma of obesity on overweight individuals. International Journal of Obesity and Related Disorders, 2004. 28(10): p. 1333.

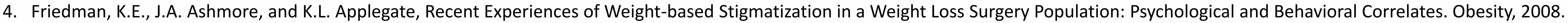
16(S2): p. S69-S74.

5. Schvey, N.A., R.M. Puhl, and K.D. Brownell, The Stress of Stigma: Exploring the Effect of Weight Stigma on Cortisol Reactivity. Psychosomatic Medicine, 2014. 76: p. 1-7.

6. Tomiyama, A.J., et al., Associations of weight stigma with cortisol and oxidative stress independent of adiposity. Health Psychology, 2014. 33(8): p. 862-867. 